\title{
La nueva normativa del régimen electoral general en España
}

\section{Francisco Fernández Segado}

\section{EL DECRETO-LEY DE NORMAS ELECTORALES Y LA EXIGENCIA CONSTITUCIONAL DE UN.A NUEVA LEY ELECTORAL}

I A LEY PARA LA Reforma Política, de 4 de enero de 1977. Lpretendia, tal y como se indicaba en el preámbulo, que en un primer nomento acompañaba al texto articulado del proyecto, "hacer posible que la mayorfa popular se constituya en la instancia decisoria de la misma reforma"; pues sólo cuando el pueblo hubiere otorgado libremente su mandato a sus representantes, podrfa acometerse democráticamente y con posibilidades de estabilidad y futuro la solución de los importantes temas nacionales a través del imprescindible proceso constituyente,

La Ley que, como seflalara Sánchez Agesta $^{2}$, suponia una resuelta afirmación de un principio democrático como fundamento del orden constitucional, iba a presentar, pues, no tanto un carficter sustancial cuanto instrumental: to que no excluye evidentemente una autorruptura con Ia formula politica franquista de democracia orgínica ${ }^{2}$

1 Lus Sdncher Aresta "La nueva Ley Fundamental para th Reforma Politica", en Reviste de Derecho Público, no, 66, esero-marzo 1977, píg. 6

2 Pablo Lucat Vertir tha Octora Ley Fundamental. Critica juridico politica de la Refoema Suarer". Techos, Madrid, 1976, pig. 71 
$Y$, en efecto, el articulado de la norma en cuestión se iba a circunscribir a sentar las bases o premisas ineludibles para la elección democrática de un nuevo órgano legislativo, esta vez bicameral; que, en su caso. habría de ser encargado de afrontar la elaboración de un nuevo ordenamiento constitucional. Desde esta óptica debe entenderse el art. 2 de lis Ley que, complementado por la disposición transitoria primera, perfilaba los trazos sustanciales del futuro Parlamento bicameral.

El inciso inicial de la citada disposición transitoria primera atribuia al Gobierno la regulación de las primeras elecciones a Cortes: bien que. más adelante, el mismo precepto, ante la insistencia de un importante sector de procuradores representado por el Sr. Martinez Esteruelas ${ }^{3}$, en el sentido de la conveniencia de fijar en la propia ley unos principios mínimos a los que el Gobierno hubiera de ajustarse en el momento de la regulación detallada de la normativa electoral, sentaría unos principiosmarco ${ }^{4}$ cuyo influjo seria, un tanto sorprendentemente, decisivo al ser en buena medida constitucionalizados por el art. 68 de nuestra "magna carta" politica.

El Gobierno, en desarrollo de la referida previsión de la disposición transitoria primera, dictaba el Decreto-Ley 20/1977, de 18 de marzo. sobre Normas Electorales que, a juicio de Alzaga s, venía impregnado del mismo sentido práctico que presidiría toda la operación política de la Reforma, de cara a facilitar la construcción de una plataforma común de convivencia. En cualquier caso, el ámbito temporal del Decreto-ley quedaba nítidamente perfilado en su art. 1 , en el que se podía leer:

"El presente Decreto-Ley, en cumplimiento de lo previsto en la disposición transitoria primera de la Ley para la Reforma Politica, tiene por objeto regular las primeras elecciones al Congreso de los Diputados y al Senado que han de constituir las nuevas Cortes Espafiolas, de conformidad con lo previsto en la citada Ley". *

3 Cr. al respecte, Cortes Espafolas, Diario de las Sosiones del Fleao, X Legislatera, No. 29, págs $92-93$.

4 Cfr. al efecto, Pablo Plrez Tremps: "La Ley para la Reforma Política Aspectos de Transición política erpatola", en Revista de la Facultad de Derecho de la Universidad Complatense, No, 54 verano 1978, pógi. 125 y sigs: en concreto, pàg. 152-164.

5 Oncar Alsage "La Constitucióa Espanola de 1978. Comentario sistemático", Fdiciones del Foro, Madrid, 1978, pig. 27.

6 Cfr. sobre el contenido del Decteto-Ley 20/1977, Luis Sinchet Agesra "Ley Electoral" Editorial Revista de Derecho Privado, Madrid, 1977 
Esto es, su vigencia temporal quedaba especificamente curcunstrita a las elecciones a Cortes que habian de celebrarse el 15 de junio de 1977 Sin embargo, no podemos ignorar que una de las constantes de todo sis. tema electoral es su inercia, su tendencia a perpetuarse; pues no en vano los intereses políticos de las distintas formaciones que participan en la lid electoral vienen mediatizados en mayor o menor medida por la normativa electoral, lo que explica que, perfilado un determinado sistema, las fuerzas mayoritarias se resistan a modificarlo por el temor a perder el beneficio que el sistema vigente les ha proporcionado; pues, como constata Rae ', tras recordar el pasaje evangélico del Nuevo Testamento "al que tiene, se le dará más y abundará: $y$ al que no tiene, aún aquello que tiene le sera quitado" " , los efectos próximos de la ley electoral sobre los partidos políticos se ajustan al entendimiento más literal del referido texto.

En efecto, si hay una pauta que surja del estudio que lleva a cabo Rae con categorfa parecida a la de "ley", es la continua parcialidad de las leyes electorales en favor de los partidos grandes y en contra de sus competidores más flojos. El partido con muchos votos obtiene escanos "en abundancia", pero el partido que no tiene tantos votos sucle obtener un menor número de escaños que su parte proporcional o, peor aún, puede no obtener ningùn escafo en absoluto ${ }^{\text {. }}$

Quizá en previsión del impacto de esta "inercia electoral", el apartado tercero de la disposición transitoria 8 a. de nuestra Constitución disponía que en el supuesto de disolución, y si no se hubiera desarrollado legalmente la previsión de los arts. 68 y 69, que al regular la composición del Congreso y Senado, se remitian -en lo que hace al especifico procedimiento de elección- a la pertinente Ley Orgánica Electoral ${ }^{10}$, serían de aplicacion en las elecciones las normas vigentes con anterioridad, esto es, las contenidas en el Decreto-Ley 20/1977, con las solas excepciones

7 Douglos W. Ree. "Leyes Electorales y Ststema de Partidos Roliticos. Estudio Comparado". Edidanea CrTE. Madrid, 1977, páz. 140

8. Sen Mateo, 13, 12 (Razón de la paribola đel stubbrador). "Nuevo Tertameato", versión đe NAcar-Columgo, B.A.C., Madrid, 1972, páe. 69.

9 No va s aer exirefla a eatu "ley" enunciads por Roe nuestri nocmativa electoral; bien al contra fo, Ie malma propicin sensibles distorsiones de la proporcionaltad. Cfr, a este respecto, fran claco Fondnder Segado: "Las distorsiones de los priacipios de foualdad de voto y propot clonallded en el Decreto-Ley de Normas Electoraies". en Rerista de Derecho Ribboo. No 102, enero marto 1985

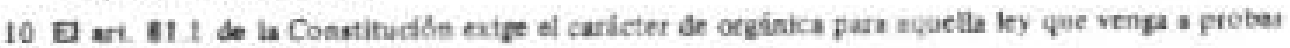
al rtgenen olectoral general. 
de que en lo referente a inelegibilidades e incompatibihdades se aplicaria directamente al art. $70.1, \mathrm{~b} / \mathrm{de}$ la Constitución (que a diferencia del Decreto ley de Normas Electorales, declaraba elegibles a los miembros del Gobierno, compatibilizándolos igualmente con el ejercicio del mandato parlamentario, en línea con la más pura tradición del parlamenta. rismo); en lo que hace a la edad de voto, ésta sería la de 18 años, de conformidad con el art. 12 de nuestro eódigo constitucional; $y$, final mente, en lo que respecta al número de senadores de carácter "provincial", sería de 208 frente a los 207 previstos por el Decreto Ley 20 / $1977^{\prime \prime}$

Y la realidad iba a corroborar la teoría. pues la normativa contenida en el tantas veces referido Decreto--ley regiria no ya los comicios de 1977. sino también los de 1979 y 1982.

Sin embargo, la necesidad de desarrollo de las previsiones constitucionales, que exigian una ley orgánica de régimen electoral se iba a hacer cada vez más acuciante, llegando el mismo Tribunal Constitucional a hacerse eco de ella. En efecto, el recurso previo de inconstitucionalidad contra el texto definitivo del Proyecto de Ley Orgánica de Incompatibilidades de diputados y senadores, era resuelto por medio de la sentencia 72/1984, de 14 de junio en la que el Tribunal considera que:

"La Ley Electoral estă prevista en la Constitución como una de las leyes necesariamente llamadas a desarrollarla. Se deduce asi. sin gran dificultad, de la lectura del art 70 , y se deduce igualmente de la disposición transitoria 8a.3. La aplicación en elecciones posconstitucionales del Decreto electoral anterior posee carácter excepcional" 12 .

El Tribunal, finalmente, estimaba el recurso al entender que la regulación de las causas de incompatibilidad e inelegibilidad debía corres. ponder, de conformidad con la prescripción del art. 70 de nuestro código político, a la Ley Electoral, que -se añade- "está prevista en la Constitución como una de las leyes necesariamente llamadas a desarrollarla" 13

I1 El escasio de diferencia se explica en base a yue, de conformidad con ef art, 69,3 de ia Constitución, las islas de Gomera $e$ Hierro eligen cada una de ellas un senador, mientras que, con anterioridad, conxtitufan confuntamente un sola distrito electoral en el que era elegido un senador

12 Sentencia del Tribunal Constitucioaal $72 / 1984$, de 14 de junio (BOH de 11 de falio), fand.

13 Ibidem. fund pur 5, ab initio 
Tal circunstancia creemos que fue el detonante decisivo que conducía al Gobierno a la elaboración y subsiguiente envio al Congreso del Proyecto de Ley Organica de Régimen Electoral General ${ }^{14}$ que, tras ser aprobado por la gran mayoría de los miembros de ambas cámaras, se convertia en la Ley Orgánica 5/1985, de 19 de junio, de Régimen Electoral General ${ }^{15}$

\section{EL PERFIL GENERAL DE LA NUEVA LEY ELECTORAL}

La nueva Ley Electoral viene a engiobar dentro de su ámbito normis. tivo a materias que con anterioridad eran objeto de tratamiento legal disperso en diferentes normas juridicas. En conereto, la ley, que segun se afirma en su preámbulo, "pretende lograr un marco estable para que las decisiones políticas en las que se refleja el derecho de sufragio se realicen en plena libertad", regula no sólo las elecciones generales, sino también las municipales sentando, asimismo, las reglas especificas para la elección de los Cahildos Insulares Canarios y de los Diputados Provinciales.

La Exposición de Motivos del Proyecto venfa a justificar este tratamiento conjunto en la determinación del art. 81 de nuestra "lex legum". que establece la necesidad de que "las Cortes Generales aprueben, con carácter de orgănica, una ley que regule el régimen electoral general" 16

"Ello - puede leerse en la Exposición de Motivos-- plantea, de un lado, la necesidad de dotar un tratamiento unificado y global al variado conjunto de materias comprendidas bajo el epigrafe constitucional 'Ley Electoral General', así como regular las especificidades de cada uno de los procesos electorales en el ámbito de las competencias del Estado".

14 E Proyecto sería pubticado en el Boletin Oficial de las Cortes Ciencrales, Congreso de los Diputados, Serie A, No, 120 - I, 15 de octubre de 1984, págs. 1775 y sles.

15. Publicada en el B.O.E. No. 147/85, de 20 de jusio, pligs. $19110 \quad 19134$, Currección de eiroses ea el B.OF. 17/1986, de 20 de enero, pig. 2759.

16 "Para que una ley merezea el catificativo de electoral - manflesta el Tribunal Cunatitucional ea 20 sentencia $72 / 1984$, de 14 de junio, fund. jor. 4 -es necesario que contenga por lo menos el núcleo central de la normativa atinente al proceso electoral, materia en la que se compren de lo relativo a quỉ́nes pueden elegir, a quiénes se puede elegir y hajo qué condiciones, para qué espacto de tiempo y hajo qué criterios organizativos desde el punto de vista procedimental verritorial* 
La Ley, que en este punto formal nos recuerda la construcición arquitectónica del "Code électoral" francés. se estructura de modo tal que pueda adecuarse a la doble filosofia a que responde cumplimiento de un imperativo constitucional inaplazable y pretensión de hacerlo desde la globalidad que la propia Constitución impone y que reconociera explícitamente el Tribunal Constitucional en su Sentencia 38/1983, en la que se sienta la doctrina de que: "El régimen electoral general está compuesto por las normas electorales válidas para la generalidad de las instituciones representativas del Estado en su conjunto y en el de las Entidades territoriales en que se organiza a tenor del art. 137 de la Constitución, salvo las excepciones que se hallan establecidas en la Constitución o en los Estatutos" 17.-

Por todo lo dicho, tal y como en su propio preámbulo se reconoce, en la Ley se va a plantear una división fundamental entre disposiciones comunes para toda clección por sufragio universal (t ftulo I) y normas que se refieren a los diferentes tipos de elecciones politicas: elecciones de diputados y senadores (título II); elecciones municipales (título III); elecciones de los Cabildos Insulares Canarios (título IV) y elección de Diputados Provinciales (título V), normas todas éstas que no son sino una modulación de los principios generales a las peculiaridades propias de los procesos electorales que el Estado debe regular ${ }^{18}$

Es obvio que al margen ya de los procesos de participación directa o semidirecta del pueblo, normativizados por la Ley Orgánica 2/1980, de 18 de enero, de regulación de las distintas modalidades de referéndum (modificada a su vez por la Ley Orgínica 12/1980, de 16 de diciembre). y de la elección de los senadores autonómicos, contemplada en su detalle por los Estatutos de Autonomfa respectivos, solo restan las elecciones autonomicas. Estas no son, como parece obvio, contempladas de modo especifico por la Ley Orgánica $S / 1985$, bien que, desde luego, buena parte de los preceptos recogidos en el título I, núcleo central de la ley y punto de referencia del resto de su contenido, deban ser considerados tal y como se advierte en el Preámbulo- presupuesto de la actuación legislativa de las Comunidades Autónomas. Y, a tal efecto, el art. 1.2 prescribe

17 Sentenda del T.C. 38/1983, do 16 de mayo (BOE de 20 de mayo), fund, jur, 3o,

18 Precisamente por ello, la Loy procede a derogar la Loy 39/1978, de 17 de julio, de Electionea Locales, asi corno th Ley Orginica 6/1983, 4o 2 de marno, que vino a modificar determinados artículos de la anterlor. Ello, stn perjukicio de que nu disposictón derogatoria deje asimisise sin efocto el propio R. Decreto-ley 20/1977 y la Ley 14/1980, de 18 de abril, sobue atgimen de 
que en los términos establecidos por la disposición adicional primera -cuyo No. 2 enumera el conjunto de artículos del título I que en aplicación de las competencias que la Constitución reserva al Estado, deben aplicarse también a las elecciones a las Asambleas Legislativas de las Comunidades Autónomas convocadas por éstas- la Ley Orgánica del Régimen Electoral General es de aplicación a las elecciones a las Asambleas de las Comunidades Autónomas, y tiene carácter supletorio de la legislación autonómica en la materia.

En otro orden de consideraciones, es preciso significar cómo la Ley que analizamos ha venido a abordar cuestiones que hasta su entrada en vigor no eran contempladas por el R. Decreto-ley 20/1977. sino que se regulaban de modo un tanto disperso. Tal sería, por ejemplo, el caso del régimen legal de las encuestas electorales, con anterioridad, regulado por la Ley $14 / 1980$, de 18 de abril, y que ahora viene a contemplar dentro de su articulado (art. 69) la nueva norma electoral.

$\mathrm{Y}$ otro tanto hay que decir en lo atinente a la utilización de los medios de comunicación de titularidad pủblica que, de conformidad con la remision a normas reglamentarias que al efecto contemplaba el art 40.1 del Decreto-ley 20/1977, seria objeto de regulación gubemamental por medio del Real Decreto 967/1977, de 3 de mayo (para los comicios de junio de 1977 y por el Real Decreto $157 / 1979$, de 2 de febrero, sobre normas aclaratorias en torno al ejercicio del derecho al uso gratuito de espacios de televisión, radio y prensa (para la consulta electoral de 1979). También esta importante materia pasa ahora a ser objeto de detallada regulación legislativa (en los arts. 59 a 67 de la Ley).

Por cuanto acabamos de señalar, la doctrina ha visto en la heterogeneidad la característica fundamental del contenido de la "nueva" normativa electoral ${ }^{19}$. En todo caso, este dato nos parece positivo, pues permite armonizar en una única norma las diferentes variables que inciden sobre la libre expresión de la soberanía popular. que es lo que en último término debe garantizar un sistema electoral en el marco de un Estado democrático.

Ahora bien, de todo lo expuesto no debe deducirse que nos hallamos en presencia de una "nueva" ley electoral, esto es, de una normativa que 
Se separa sustancialmente de la precedente Bien al contrano. st al efecto hubiéramos de resaltar algun rasgo. ése serla el de la "continusdad"

La L. O 5/1985, en lineas generales, no hace sino reproduct la normativa dispersa, pero ya existente con anterioridad, tai circunstancia es especialmente significativa en lo que atane al sistema electoral propiamente dicho, que se mantiene prácticamente inalterable, Ello, por otra parte, habría de propiciar el consenso parlamentario en torno a esta ley, bien que a costa de mantener las graves distorsiones de la proporcionalidad que el análisis empirico de las elecciones generales de 1977, 1979 y 1982 corrobora con verdadera nitidez ${ }^{20}$

Es cierto que el PS.OE disponia de la mayoria absoluta necesaria para sacar adelante por si solo esta ley, impregnándola de tintes marcadamente partidistas; no to hizo, y es de alabar tal renuncia, mucho màs cuando la historia nos pone de relieve una sucesión ininterrumpida de normas electorales hechas a la medida de un determinado interes de partido; pero no es menos evidente que el mantenimiento del sistema existente era la mejor garantia para el partido mayoritario en ambas cámaras $-y$ también, desde luego, para la oposición representada por Coalición Popular y, en menor medida, para las dos formaciones nacionalistas, vasca y catalana- de que sus intereses electorales iban a seguir gozando de una especial salvaguarda: la que otorga nuestra normativa a las dos grandes formaciones del arco parlamentario, pues, a nuestro juicio, es evidente que las distintas variables que contribuyen a perfilar nuestro sistema electoral no sólo benefician sobremanera al partido mayoritario ${ }^{21}$, sino que también, en menor medida, la segunda formación política se ve favorecida, con lo que, en conjunto, el bipartidismo resulta potenciado por la incidencia global del sistema, a salvo tan sólo el influjo del sistema sobre los dos grandes partidos nacionalistas que al concentrar su voto en un reducido ámbito geográfico, obtienen un porcen-

$20 \mathrm{Cfr}$, a este respecto, Franclseo Ferndndez Segado: "Las variables conformadoras de nuestro sistema electoral (1977 1985) y su incidencla sobre el sistema de partidos". Ponencla presentada a las Jornadas de Estudio sobre "Las Cortes Generales", organizadas por el Cuerpo Sapertor de Letrados del Estado (Ministerio de Justicia). Madrid, mayo oe 1985 (de próxima publt. cación)

21 Como han puesto de relieve Dieter Nohlen y Rainer-Otaf Schal tze (en "Los efoctos del sistema electoral espanol sobre hi relación entre sufragios y cscanos. Un estudio con motho de las elecelones a Cortes de aetubre de $1982^{2 \prime}$ en Revista Espaffola de Investigaciones Sociológlicas. No 30, abril/junio 1985, púgs 179 y sigs. en concreto, páf 191) cuanto mayer sea la fraaldad en los porcentajes de votos entre los partidos segundo, tercero y cuarto, tanto mis se benefo. clard di sistema electoral el partido mayoritario 
taje de escanos bastante proporcionado al correspondiente de votos logrados 22 , cuando no superior, cual ha sido el supuesto habitual del P.N.V. ${ }^{23}$

Hechas estas consideraciones generales, vamos a pasar at analizar en detalle los aspectos más significativos de la ley.

\section{LAS DISPOSICIONES COMUNES PARA LAS ELECCIONES POR SUFRAGIO UNIVERSAL DIRECTO}

La Ley Orgánica $5 / 85$, de 19 de junio, dedica el título I tarticulos 2 al 153) a regular aquellos aspectos del proceso electoral que, con algunas salvedades para las elecciones autonómicas, habrán de regir para todos aquellos procesos en los que el cuerpo electoral proceda a elegir representantes a través del sufragio universal.

Con carácter somero, vamos a abordar algunos de los aspectos que estimamos más trascendentales de la Ley: a) el derecho de sufragio y el censo; b) la Administración Electoral; c) el procedimiento electoral. d) la regulación a que queda sujeta la utilización durante la campaña electoral de los medios de comunicación de titularidad pública; e) el régimen de las encuestas electorales y, por último, f) la concreción legal de los gastos y subvenciones electorales.

\section{A) El derecho de sufragio y el censo}

La Ley dedica los primeros capitulos del título I al derecho de sufragio activo y pasivo, esto es, al derecho de participar como elector en los comicios $y$ al derecho a ser candidato en unas elecciones.

El sufragio activo, en armonía con la previsión del art 23.1 de nuestra "lex legum". que reconoce el derecho de todos los ciudadanos

22 En anjiogo sentido se pronuncia fuan Carlos Gonzalles Herndndez: "Desigualdades de repre sentición en la notmativa electoral vigente", en el colectiono "Los procesos de formación de las Comunidades Autónomas, Aspectos juridicos y perspectivas politicas", vol. 1, Granada 1984. págs. 161 y sigs, en concreto, pág. 167

23 Como regla zeneral, maniflestan Dieter Nohlen y Rainer-Olaf Schulize (en "Los efectos dei sistema electoral español ", op. eit., pie. 192). los purtidos pequedos mejorarán sustan cialmente sus oportunidades de representación si concentran wa potencial electoral en deter minedas circunscripciones, en lagar de extenderlo uniformemente por toda el área electoral 
a "participar en los asuntos públicos, directamente o por medio de representantes libremente elegidos en elecciones peribdicas por sufragio unversal", se atribuye a los espanoles mayores de edad que no estén com. prendidos en ninguno de los supuestos a que se refiere el art. $3^{24}$ precepto éste cuyo rasgo más significativo es el de la garantía que supone la intervención judicial que en él se prescribe. En efecto, no puede pro varse a ningún ciudadano del derecho a votar en unos comicios si no es previa decisión de la pertinente autoridad judicial, a la par que, según se explicita en el art. 5. tampoco nadie puede ser obligado o coaccionado bajo ningun pretexto en el ejercicio de su derecho de sufragio, ni a revelar su voto.

El ejercicio del derecho de sufragio quedu en todo caso sujeto a un requisito administrativo, pero no por ello menos importante: la inscripción en el censo electoral vigente (art. 2.2).

El censo, que ha sido considerado como uno de los inventos que más ha facilitado el progreso del arte de gobernar ${ }^{25}$, puede enmarcarse apropiadamente, como ya significara el maestro Giménez Ferzández ${ }^{26}$ dentro de las garantias del sufragio, pues no en vano se dirige a evitar la suplantación de la persona del elector a la par que, desde luego, pretende evitar que algún ciudadano pueda votar más de una vez en las mismas elecciones, to que expresamente prohibe la ley (art. 4.2).

Precisamente, en orden a la más nftida identificación del elector y a la evitación del fraude electoral que supondría toda duplicidad, el Grupo Popular del Congreso de los Diputados, en sus enmiendas Nos 550,551 y 552 , postularía la necesidad de que junto al nombre y apellidos del elector, se incluyera en los datos censales el número del Documento Nacional de Identidad, "como dato referencial que permitirá garantizar más eficazmente que no existen duplicidades" 27 . Tal peticion seria denegada en un primer momento por el Informe de la Ponencia (que

24 Los trea inpuestot en lon que al art. 3.1 priva del derocho do stafrago actiro a espaloles mayo. rea de odad soa: a) condona por sentencia judictal firme a la peas princlpal o socesotis de

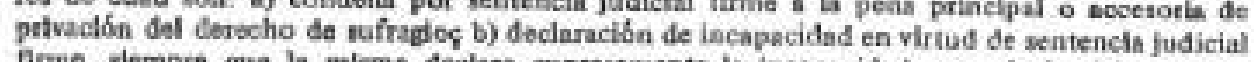
inme, slempie que la misma declare expresamente la inchpacidad para el ejercicio de este

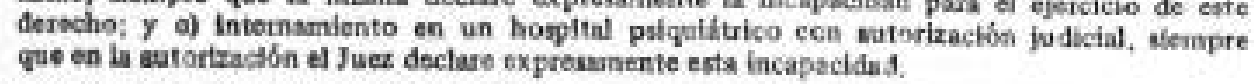

25 W.J.M. Mackenuile: "Elecciones Hbies", Tocnon, Madrid, 1962, pág, 125.

26 Mamuel Gimenes Fernitnder: "Estudios de Derecho Electoral Cuntrmporinea". Pubticaciones de ta Universidad de Sevills, 2a. ed., Sevilla, 1977, pies 164

27 Justificacion do la enmienda No. 552 ald Onepo Fupular 
rechazaba las tres enmiendas) por considerarla perturbadora en tanto en cuanto podía propiciar errores censales ${ }^{28}$. Sin embargo, ya dentro del debate en el seno de la Comisión Constitucional, el diputado socialista Sr. Marcet i Morera, tras manifestar que su Grupo no tenia ninguna prevención de carácter político ni de ningún otro tipo respecto a la inclusión en los datos censales del número del DNI, manifestando tan sólo una preocupación acerca de que tal hecho pudiera dar lugar a mayores errores en el censo, pondría de relieve la aceptación por parte de su Grupo de la inclusión en el censo del dato de referencia "como un elemento de seriedad y de contrastación de este censo para evitar posibles duplicaciones" ${ }^{29}$, ofreciendo al respecto la transacción de incluir en el articulado la necesidad de que en el censo conste el número del DNI de cada ciudadano-elector, bien que previéndose a la par en la ley (en su disposición adicional tercera) que el Gobierno dispondrá del plazo de cinco años desde la vigencia de la propia ley para dictar las normas precisas para poder hacer efectiva la inclusión entre los datos censales del número del DNI.

Otro dato significativo de la ley (art. 33.5) es el de la previsión por la misma de que todos los electores habrán de recibir de la Administración Electoral una "Tarjeta Censal" con los datos actualizados de su inscripción en el Censo electoral, así como de la Sección y Mesa en que les corresponde votar.

El censo electoral, que es permanente, debe ser revisado en los términos de los arts. 35 y sigs. de la ley, anualmente, con fecha del primero de enero de cada afo, previsión ésta que prácticamente está transcrita del art. 16 del "Code électoral" francés.

Para cada consulta electoral ha de utilizarse el censo vigente el dfa de la convocatoria. Sin embargo, la nueva Ley de Régimen Electoral General, a diferencia del Decreto-ley 20/1977, contempla con gran amplitud la rectificación del censo en período electoral, sujetándola además en último término a la garantía judicial.

En efecto, los Ayuntamientos y Consulados vienen obligados a la

28 Isforme de la Ponencis sobre el Proyecto de Ley Orgínica de Réginen Electoral General. B.O.C.G., Congreso de los Diputados, 11 Legislatura, Serte A, No, 120-1-4, 21 de marzo de 1985. píg. 1816/11.

29 Diario de Sesiones del Congreso de lou Diputados, II Legialatura, No, 286 (Conisión Constitucional), 26 de marzo de 1985, pís. 8941. 
exposición de las listas electorales vig nt s de sus respectivos Municipıos el quinto día sucesivo a la convocatoria de elecciones. En los ocho dias siguientes, cualquier persona puede presentar reclamación administrativa ante la Delegación Provincial de la Oficina del Censo Electoral sobre su inclusión o exclusión en el censo, vinendo obligada en tal supuesto la citada Delegación a resolver, en el plazo de tres dias, las reclamaciones presentadas, ordenando al efecto las rectificaciones pertinentes que. además, habrán de ser expuestas al público el decimoséptimo día posterior a la convocatoria. En todo caso, tal y como prevé el art, 40 de la ley. contra las resoluciones de la Oficina del Censo Electoral podrá interponerse recurso ante el Juez de Primera Instancia en un plazo de cinco dias a partir de su notificación. La pertinente sentencia judicial deberá dictarse a su vez en el plazo de cinco días, agotando la vía judicial.

En otro orden de consideraciones, significaremos por último que la ley enumera con detalle en su art. 6 las causas de inelegibilidad, separando las que pueden ser consideradas como causas de inelegibilidad absoluta por afectar a cualquier circunscripción electoral, de aquellas otras que tienen un carácter relativo, pues sólo impiden a quienes incurren en ellas el ser elegidos por determinadas circunscripciones electorales: aquéllas que estân comprendidas en todo o en parte en el ámbito territorial de la jurisdicción que ejercen (así, por ejemplo, quienes ejerzan la función de mayor nivel de cada Ministerio en las distintas demarcaciones territoriales de ámbito inferior al estatal, los delegados territoriales de RTVE, los Secretarios Generales de las Delegaciones del Gobierno y de los Gobiernos Civiles, los Delegados provinciales de la Oficina del Censo Electoral etc.)

En todo caso, la calificación de inelegible solo procederá, respecto de quienes incurran en alguna de las causas legalmente enumeradas, el mismo día de la presentación de la candidatura, o en cualquier momento posterior hasta la celebración de las elecciones, to que deja abierta la posibilidad de que, tras la convocatoria de los comicios y hasta el momento de presentación de candidaturas -que tiene lugar entre el decimoquinto y el vigésimo día posteriores a la convocatoria-, pueda cesar en el cargo que genera la enelegibilidad quien desee ser candidato $o$, si se trata de un magistrado, juez, fiscal, militar profesional o de complemento o miembro de las Fuerzas y Cuerpos de Seguridad y Policía, en activo, solicitar el pase a la situación administrativa que corresponda.

Refirićndonos ya, en concreto, a las normas especificas para las elecciones de diputados y senadores, el art 154 de la ley determina la 
inelegibilidad de: a) quienes ejerzan funciones o cargos conferidos y remunerados por un Estado extranjero; $y$ b) por lo que respecta al Congreso de los Diputados, los Presidentes y miembros de los Consejos de Gobierno de las Comunidades Autónomas, asi como los cargos de libre designación de dichos Consejos y los miembros de las Instituciones Autonómicas que por mandato estatutario o legal deban ser elegidos por la Asamblea Legislativa correspondiente. Por lo demás, cabe significar que nadie puede presentarse simultáneamente como candidato al Congreso de los Diputados y al Senado.

Siguiendo las premisas del art. 70 de la Constitución, que, como ha subrayado el Tribunal Constitucional ${ }^{30}$, perfila un sistema de concurrencia de supuestos de inelegiblidad, que impiden el convertirse, en quien concurran, en sujeto pasivo de la relación electoral, y de supuestos de incompatibilidad, en los que se transforman los de inelegibilidad, operando. en su caso, impidiendo el acceso al cargo o el cese en el mismo, de modo que aquéllos proclamados, $y$ aun elegidos, que han quedado posteriormente afectados por tales causas, incurren en incompatibilidad Siguiendo, decimos, estas premisas, el art. 155.1 de la L.O. 5/1985 prescribe que "las causas de inelegibilidad de los Diputados y Senadores lo son también de incompatibilidad". Con ello, como remarcara el supremo intérprete de nuestra "lex legum", la causa sobrevenida opera así como supuesto de incompatibilidad generadora, no de la invalidez de la elección, sino de impedimento para asumir el cargo electivo o de cese, si se hubiera accedido al escaño.

Además, y a renglón seguido, el propio art. 155.2 enumera otras causas diferentes de incompatibilidad (Presidente del Tribunal de Defensa de la Competencia, miembros del Gabinete de la Presidencia del Gobierno. miembros del Consejo de Administración del Ente Público RTVE... etc.)

$\mathrm{Y}$, a todo ello, hay que afiadir la interdicción especifica del art 67.1 de nuestra Constitución de que nadie pueda ser miembro de las dos Cámaras simultáneamente, ni acumular el acta de una Asamblea de Comunidad Autónoma con la de Diputado al Congreso

30 Setencia del Tribunal Constituciosal 45/1983, de 25 de mayo (BOE de 17 de junio), fund jur 5 
La Administación Electoral, integrada por las Juntas Electorales. Central, Provincial, de Zona y, en su caso, de Comunidad Autónoma. asf como las Mesas Electorales, tiene por finalidad garantizar en los términos de la propia Ley Electoral la transparencia y objetividad del proceso electoral y del principio de igualdad, tal y como prescribe el art 8 de la ley en su apartado primero. precepto éste incorporado a la norma en cuestión por virtud de la enmienda No. 141 del Grupo Parlamentario Vasco del Congreso, que entendía necesario proceder a definir las finalidades de la Administración Electoral antes de regular su estructura y organización.

La trascendencia de la función de la Administración Electoral es obvia y, en lógica conexión con ella, parece evidente que es imprescindible el que se garanticen los medios necesarios para que los casos que se planteen con respecto a la ley electoral se resuelvan con justicia y al margen del control del Gobierno, porque, como advirtiera Mackenzie ${ }^{31}$. siempre cabe la sospecha de que, ocupando éste el Poder, intente "arreglar" las elecciones a su propia conveniencia. De ahí que la solución de todas las cuestiones que pudieran solventarse al hilo del proceso electoral sólo pueda encomendarse a cuerpos eficientes e independientes de funcionarios $y$ jueces ${ }^{32}$.

Pues bien, nuestra actual normativa, entre los posibles sistemas por los que se podía optar, se ha decantado, con muy buen criterio a nuestro modo de ver, por una Administración Electoral que presenta un perfil inequívocamente judicial, con lo que se ha acunado una solución más sencilla y diáfana que la trazada por el Decreto-ley 20/77 ${ }^{33}$.

31 W.J.M. Mackenale: "Elecciones tibres", op. cit "pig. 109.

32 No hay atstema, por noblo que sea - significa Mackenzie (op. cit., pág 110). que inspire conflenxa si lo spliean hombres que se hallan a las 6rdenes directas del Gobiemo,

33 Así, recordemos al ofecto que la Junta Electoral Central estaba presidida, de conformidad con el Decreto- loy de Norma Electorales, por el Presidente del Tribural Sapremo e integrada por 16 Vocalos: cineo Magistrados del Tribunal Supremo, el Consejero permanente de Estade de meyor antigledad en el eargo, tos Presidentes de las Reales Acsdemias de Clencias Morales y Políticas y de Jariaprudeneta y Lezidadín, al Fresidente del Consejo General de la Abogacia of Preaidente de la Jua ta de Decanos de Colegios Notariales de Fiparia, un Catedrítico de algu na de ha Facaltades de Derecho que radiquea en Madrid y hasta cinco Vocales, desienados por Decteto, previs propuesta oopfunta do la asociacioses, federacioses y coaliciones que presen taran candidatos en mís de velaticinoo distritos, dirigjda al Goblemo una ver proclemadas las 
En efecto, aun cuando la regulación precedente no era sustancialmente distinta, pues la composición de las Juntas Electorales giraba en tomo a los miembros de la magistratura, considerados. por su misma función, garantes de la objetividad, lo cierto es que a ellos se unian, al margen ya de los representantes del propio electorado que en las Juntas Central y Provinciales participaba a través de Vocales propuestos por las fuerzas políticas contendientes-, los representantes de Corporaciones jurídicas y docentes, cuya presencia se justificaba en base a la lógica presuposición de su conocimiento de las técnicas jurídico públicas. Este tríptico en el que se basaba la composición de los órganos de la Administración Electoral implicaba el que éstos se nos presentaran con un perfil un tanto híbrido y complejo, a la par que con una composición excesivamente amplia.

La normativa actual ha operado en un doble sentido esencial: otorgando un inequívoco perfil judicial a los órganos de la Administración Electoral y simplificando su composición. Un perfil judicial que resulta del hecho de que tanto en la Junta Electoral Central como en las Provinciales $y$ de Zona hay una primacfa numérica de los miembros del Poder Judicial: ocho Vocales Magistrados del Tribunal Supremo, sobre un total de trece, en la Junta Electoral Central; tres Vocales, Magistrados de la Audiencia Provincial correspondiente, sobre un total de cinco, en las Juntas Provinciales; y tres Vocales, Jueces de Primera Instincia o Instrucción, sobre un total de cinco, en las Juntas Electorales de Zona. Una sim. plificación en la composición de las Juntas que se proyecta en una doble dirección: a) mediante la supresión del grupo de Vocales que con anterioridad representaban a Corporaciones jur fdicas y docentes; $y$ b) mediante la reducción del número de Vocales de las Juntas (la Junta Electoral Central ve reducido el número de sus miembros de 17 a 13; las Juntas Provinciales, de 9 a 5 ; $y$ las Juntas de Zona, de 7 a 5 ).

La eleccion de los Vocales integrantes del Poder Judicial no presenta problema alguno ya que son designados mediante insaculación. Por el contrario, si que ofrecía problemas la designación de los Vocales que habíen de representar al electorado. Sin embargo, también en este punto se ha llegado a nuestro modo de ver a una solución satisfactoria que refuerza la independencia e imparcialidad de estos órganos, al soslayar. a diferencia de lo que sucedfa en el texto inicial del Proyecto del Gobierno, toda interferencia gubernamental.

En efecto, mientras el Proyecto prevéa que la designación de los Vocales de la Junta Electoral Central, que habían de representar a los 
partidos. federaciones, coaliciones .... etc., sería hecha por el Gobierno. oidos los grupos políticos presentes en el Congreso, si transcurridos noventa dias desde la sesión constitutiva de la Cámara, ésta no hubiese efectuado la pertinente propuesta, el texto definitivo de la ley, en especial por virtud del espíritu de las enmiendas números 464 (del Grupo Parlamentario Minoría Catalana). 561 y 562 (del G.P. Popular), ha optado por una solución más lógica, y desde luego, que previene frente a una intervención arbitraria del Ejecutivo. Con arreglo al art. 9.2. cuando la propuesta de los Vocales antedichos no tenga lugar en ese plazo de noventa días, la Mesa del Congreso procederá a la designación, oidos los grupos políticos presentes en la Cámara y atendiendo a la representación exis tente en la misma ${ }^{34}$

Diremos por última que la L.O. 5/85 incluye dentro del capitulo dedicado a la Administración Electoral una sección referida a la Oficina del Censo aun cuando tal órgano no integra la Administración Electoral. La citada Oficina, que se encuadra en el Instituto Nacional de Estad ística, es el órgano encargado de la formación del censo electoral y ejerce sus compe tencias bajo la dirección y la supervisión de la Junta Electoral Central

34 Algo anilogo sucedería con los dos Vocales que en representación de las candidaturas ya peoclamadas, deben set elegidos en las Juntas Electorales Provinciales y en las de Zona.

E1 Proyecto del Gobierno determinaba, al efecta que los Vocales pertenecientes a las Juntas Provinciales serian nombrados por Ordea del Ministerio del Interior, una vez proclamadas las candidaturas; a cuyo fin, los representantes de éstas psopondrían conjuntamente, a través del Gobierno Civil, las personas que hubieran de desempenar estos cargos, procediendo el Minis terio del Interiot al nombramiento - se habia de suponer que bibremente- cuando tal pro puesta no hubiese sido formalizada antes del inicio de la campoîla electosal. Otro tanto suce dia con los dos Vocales de las Juntas Electotales de Zona, con ha sola diferencia de que en este supoesto la autoridad administrativa competente para el nombramiento en el Gobernador Crivi.

El diputado del Grupo Popular, Sr. Altaga, criticaria con acritud estas previsiones, manifestando al repecto: "Nosotros creenos que las santas manos de los Cobernadores Civiles, cuando ve introducen en estas materias, pueden ser cuasi pecaminosas" (Intervención de Oscar Alzagu en defensa de la eamienda del Grupo Popular de devolución al Gobierno del Proyecto de Ley Orgánica de Rézimen Electoral General. Diario de Sesiones del Congreso de los Diputados, II Legislatura, No, 174,5 dictembre 1984, pág. 8070).

Finalmente, y a propuesta de sendas enmiendas de los Grupos Parlamentarios Minoría Catalana. Popular, Vasco y del Si, Carrillo, sería parcialmente acogida la preocupación tatente en las mismas en el sentido de garantizar nitidamente la imparciatidad e fndependencia de las Juntas Electorales y la no interferencia gubernamental en las mismas; $y$, a tal efecto, la Ponencia constituida en el seno de la Comisión Constitucional del Congreso daría ana nueva redacción al texto de su Informe que, a la postre, habria de set la definitiva.

De acuerdo con la normativa de in Ley, los dos Vocales de his Juntas Electorales Provinciales deberín ser nombrados por la Janta Electural Central si la propoesta conjunta de fos reptesen. tanses de las candidaturas proclarnadus en el distrito no se ha verificado antes del comienzo de la campaha electoral En cuanto a los dos Vocales de las Juntas de Zona, en supuesto seme jante, serín nombrados por la Junts Electoral Pruvincial 
El hecho de que este organo esté dotado de importantes competencaas ientre ellas, las claboración de las listas electorales provisionales y las definitivas, y la resolución de las reclamaciones contra las actuaciones de los órganos que participan en las operaciones censales y el que en el Proyecto gubernamental quedase adscrito tan sollo al Instituto Nacional de Estadistica, órgano a su vez dependiénte de un Minssterio, motivaria la presentación de varias enmicndas (entre otras, las números 2 , del diputado St. Bandrés: 1 20, del G.P. Vasco y 553. del Grupo Popular), orientadas en general a desvincular la Oficina del Censo del IN.E.: finalmente. 1a Ponencia aceptaria parcialmente la propuesta del Grupo Popular, en el sentido de que esta Oficina quedase bajo la dependencia orgánica de la Junta Electoral Central.

\section{C) El procedimiento electoral}

La L.O. 5/85 dedica el capitulo 6 de su título I al procedimiento éectoral, en una regulación auténticamente minuciosa y casuistica. Cuatro son los momentos centrales del procedimiento electoral: I) la presentación y proctamación de candidatos; 2) la campaña electoral: 3) la votación; y 4) el escrutinio y la proclamación de candidatos electos.

Hay que señalar que de modo general y salvo en los supuestos de disolución anticipada, los Decretos de convocatoria de elecciones -que. obvamente, marcan el inicio de la carrera electoral-se deben expedir el dia vigésimo quinto anterior a la expiración del mandato de las Cámaras y Corporaciones Locales, debiendo contener la fecha de los comicios, que habrán de celebrarse necesariamente entre el quincuagésimo cuarto y el sexagésimo dias desde la convocatoria, con lo que se da cumplimiento al art. 68.6 de nuestra Constitución, que exige que las elecciones tengan lugar entre los treinta dias y los sesenta a partir de la terminación del mandato de las Cámaras, optandose, pues, por abreviar los plazos al minimo posible.

1. En lo que se reficre a la presentación de candidaturas, cabe significar como dato más relevante de la nueva normativa electoral el agravamiento de las condiciones exigidas respecto de las agrupaciones de electores, que necesitarán para presentar candidaturas en las elecciones al Congreso y Senado del respaldo del 1 por 100 de los inscritos en el censo electoral, mientras que el Decreto-ley 20/77 exigía tan sólo el resplado del 1 por 1000 de los censados (siempre que como minimo fuesen 500 ). 
Todo elio no hace sino incrementar aún mas si cabe el menopolio de los partidos en el proceso electoral.

Es de resenar igualmente que al L.O que nos ocupa, aun manteniendo el carácter individual de las candidaturas para el Senado, prevé la posibilidad de que las mismas puedan agruparse en listas a efectos de presentación y campaña electoral.

Las candidaturas -que deben presentarse ante la Juntat Elcctoral que en cada caso corresponda, entre el décimoquinto y el vigésimo día posteriores a la convocatoria - deben ser proclamadas, cuando haya lugar a ello, mediante su publicación en el B.O.E. (en el supuesto de elecciones generales) el vigésimo octavo día posterior a la convocatoria.

Gran importancia tienen los recursos (en via judicial y en vía de amparo) que contempla la ley (art. 49) contra la proclamación de candidaturas y candidatos. En el plazo de dos días a partir de la proclanación. cualquier candidato excluido, así como los representantes de las candidaturas proclamadas o cuya proclamación hubiera sido denegadia, podrá interponer recurso contra los acuerdos de proclamación de las Juntas Electorales ante el Juzgado de lo contencioso-administrativo. La resolución judicial correspondiente debe de dictarse en los dos días siguientes a la interposición del recurso, teniendo carácter firme e inapelable, sin perjuicio del procedimiento de amparo ante el Tribunal Constitucional. El amparo debe solicitarse en el plazo de dos días, habiendo de resolver el Tribunal sobre el mismo en los tres días siguientes. Como puede apreciarse, el derecho de sufragio pasivo está perfectamente garantizado por la ley.

2. La campaña electoral, esto es, el conjunto de actividades licitas llevadas a cabo por los candidatos, partidos, federaciones, coaliciones o agrupaciones en orden a la captación de sufragios, comienza el día trigésimo octavo posterior a la convocatoria, extendiéndose por un plazo que oscila entre 15 y 21 días, debiendo terminar, en todo caso, a las cero horas del día inmediatamente anterior a la votación ${ }^{35}$

Durante la campaña, las Juntas Electorales Provinciales y de Zona

35. La loy contempla, asimismq la realización en periodo electoral pot los pudeics puibicon de una canpafia de caricter inatitucional destinada a informas e incentivar la participactón en las elecciones, sin thflair en la ortentación del voto de los electores 
asumen competencias muy diversas en relacion con los actos de la misma asi. a las primeras corresponde asumir las atribuciones enconiendadas a la autoridad gubernativa por la legislación reguladora del derecho de reunión; a las segundas. la distribución equitativa de los emplazamentos disponibles, según los Ayuntamientos, para la colocación gratuita de carteles de propaganda electoral. La ley preves, de otro lado, la interdicción de toda discriminación en cuanto afecta al derecho de las diferentes candidaturas a contratar la inserción de publicidad en la prensa periódicat. emisoras de radio y cualquier otro medio de difusión privado.

Sin embargo, hoy por hoy, sc presenta como clave en una campana electoral la utilización de los medios de comunicación de titularidad pública, aspecto al que nos referiremos más adelante y respecto del cual sí que existe una cierta discriminación.

3. La L. O, 5/85 contempla dos modalidades de volacion: por correspondencia y por personación del elector ante la correspondiente Mesa Electoral. Cabe recordar aqui que las circunscripciones se dividen en Secciones Electorales, incluyendo cada una un número de clectores que oscila entre 500 y 2000 , debiendo contar cada término municipal por lo menos con una Sección. En cada Sección hay una Mesa Electoral, aun cuando la Delegación Provincial de la Oficina del Censo, a propucsta del Ayuntamiento correspondiente, puede disponer la formación de otras Mesas, distribuyendo entre ellas el electorado de la Seccion.

4. Terminada la votación, comienza, acto seguido, el escrutínio, que es público y no debe suspenderse, salvo causas de fuerza mayor. Cada Mesa debe hacer públicos inmediatamente los resultados. El quinto día siguiente al de la votación se realiza por la Junta Electoral competente el escrutinio general ${ }^{36}$, que debe concluir no más tarde del dia noveno posterior al de los comicios, disponiendo los representantes y apoderados de las candidaturas, a partir de ese momento. de un plazo de dos días para presentar las reclamaciones y protestas que consideren pertinentes. La Junta Electoral resolverá sobre las mismas en el plazo de dos días. efectuando la proclamación de candidatos electos no más tarde del día décimocuarto posterior a los comicios.

También en este supuesto la ley establece la oportuna garantía

36 En las elecciones al Conereso o al Senado, Iss Juntas Electorales cumpetenter para la realisa dión de todas las operaciones de escrutinio genefal son las Juntas Electorales Provinciales 
de. Is intervención judicial a través del liamado recurso contencioso electoral. Fste recurso puede presentarse contra los acuerdos de las Juntas Electorales sobre proclamación de electos dentro de los tres días siguientes al acto de proclamación. De él conoce la Sala de lo contencioso administrativo del Tribunal Superior de Justicia que corresponda, Contra la sentencia pertinente no procederá recurso contencioso alguno, ordinario ni extraordinario. Digamos, por ulltimo. que estos recursos tienen carácter de urgentes, gozando de preferencia absoluta en su sustanciación $y$ fallo.

\section{D) La utilización de medios de comunicación de titularidad priblica}

Estamos en presencia de la cuestión cuya regulación legal ha suscitado, en todo momento, mayor controversia política; no en vano su trascendencia sobre los resultados electorales está fuera de toda duda.

Por otra parte, en cada una de las tres ocasiones en que se ha procedido a regular este tema se ha atendido a principios no enteramente coincidentes.

El R. Decreto $967 / 77$. de 3 de mayo (que desarrollaba el art. 40 del Decreto-ley 20/77), optaba para la utilización de espacios en RTVE por atender al criterio del númeo de distritos electorales en que se presentaran candidaturas ${ }^{37}$. Con anterioridad a los comicios de 1979, una nueva norma, supuestamente aclaratoria de la anterior, el R. Decreto 157/79. de 2 de febrero, se inclinaba -en lo que se refiere a la elección de los dias y horas de emisión - por atender al criterio de la formación y entidad

37 E.1 at. 2 del R. Decreto $967 / 77$ diferenciaba a lus grupas y entidades políticos fa los efectos de su utilizacion de los espacios de TVE) segin presentaran candidaturas en 25 o mis distritos electorales o en menos de 25 distritos, distinguiendo a su vez con respecto n estos últionos aquellos grapos y entidades que presentaran candidataras en cuatro o más distritos cuyo numero de electotes superara ol 20 o/o del total nacional. A los primeros se les otorgaban tres espacios de diez minutos en la programución nactonal más otro tambín de diez en lo regional.

A low segundos, dos de diez mimutos en la programación del ceatro regional al que correspondieran los tistritros en lus que presentaran candidaturs. A los últimos, adernás de los dos espacios precedentes, se ha sigmaba un espacto adicional de diez mimutos en la programacibo
ascional det TVF 
de los Grupos Parlamentarios del Congreso ${ }^{36}$. conjugándolo con el precedente

Pues bien, la L.O. 5/85 opta por una nueva fórmula de distribución de tiempo gratuito de propaganda electoral en cada medio de comunicación de titularidad pública: una fórmula que combina el criterio del número de votos de cada partido o coalición en las anteriores elecciones equivalentes con el del número de circunscripciones en que presenten candidaturas las respectivas formaciones políticas ${ }^{39}$.

El nuevo sistema, a diferencia de las anteriores, prima de modo sensible a las formaciones políticas que mayor apoyo del cuerpo electoral obtuvieron en las precedentes elecciones, lo que, desde luego, y dada la trascendencia de la utilización de los medios públicos de comunicación (en especial, de la televisión), representa un importante mecanismo de fortalecimiento del "statu quo" político-parlamentaria y. a la par. a nuestro modo de ver, un factor discriminatorio de dudoso encaje con la previsión constitucional del art. 23.2. En semejante dirección se pronunciarian en el debate parlamentario los representantes de las distintas minor ias $^{40}$; y asi, por ejemplo, el diputado Sr, Rodriguez Sahagin manifestar ia su parecer de que "se está ante un tratamiento absolutamente

38 H art, 2 del R. Decreto I57/79 prescribia una seria de criterios para la elección por los distintos grupos o entidades de los dís y horas de emisión de la totalidad de los espacios a que tuvie ran derecho.

En primer lugar, elegirian 1a totalidad de sas espacios aquellos partidos o coaliciones que en las anteriores Cortes hubieran mantenido un grupo parlamentario en el Congreso, estable. ciéndose un derecho prefenente de elección sejuin el numero de escanos. Flegirian en segundo térmiao los restantes gropos que presentaran candidaturas simultáneas al Congreso y Senado en más de 25 distritos. En tercer hugar, aquéllos que presentaran casdidaturas en auatro o más distritos cuyo nimero de electores superes el 20 olo del total nacional. Finalmente elege. rian los restantes grupos, en fanción del número de eandidates que presentaran,

39 Establece el art. 64 de ta ley que la distribucibn de tiempo gratuito de propapanda electoral en cada medio de comunicación de titularidad pública se efectuari conforme al siquiente baremo: a) Diez minutos para las fuetzas qee ao concurrieron o no obtuvieron reptesentación en las anteriores elecciones equivalentes o para las que, habä́ndola obtenido, no hubieran akanxado el 5 ofo del total de wotos válidos emitidos en el territorio nacional o, en sa caso, en ba circunscripciones comprendidas ca el correspondiente ámbito de difusión del medio;

b) Veinte minutos para las fuercas que, habiendo obtenido reptesentactón ea las anteriores elecciones equivalentes, dicanzaran entre el 5 y el 20 \% $\%$ del total de votos; e) Treinta minutos si eso porcentaje fuese igual o superior al 20 ojo,

En todo caso, el derecho anterior queda supeditsdo a que las respectivas formaciones politicas presentes candidaturas en más del 75 ofo de las clscunscripciones corraprendidas en el aimbito de ḋfasión 0 , en su easo, de programación del medio corresponciente. Sin ematargo, las fuerzas que, no cumpliendo este requisito, hubieren obterido en ha precedentes elecciones el 20 o/o de los rotos emitidos en el ámbito de una Comunidad Autónoma, tendrán derecbo a diez minutos de emaidión en la propramacíón general de los medios nadonales.

40 En tal sentido se pronundarian, entre otros, los fiputados Sres. Vicens i Giralt, Rodrígues Sahagin, Carrillo y, desde otra ópulea, et Si. Vizcaya Retana. DSCD, Comisión Constitucional. II Lreistatura, No. 287, 27 de marzo de 1985, puigs. 8957 y sigs. 
discriminatorio que no se corresponde cen el sentido de equidad" y con el que el Grupo mayoritario intenta "perpetuar la actual situación" 41 .

Significaremos, por último, que la autoridad competente para lat distribución de los espacios gratuitos de propaganda electoral, que ste emiten por los medios de comunicación públicos, es la Junta Electoral Central, bien que ésta disponga la emisión a propuesta de una Comisión de Radio y Televisión, designada por la propia Junta e integrada por un representante de cada partido, federación o coalición que, concurriendo a los comicios ya convocados, cuente con representación en el Congreso; siendo de notar, sin embargo, que los acuerdos de esta Comisión se adoptan con arreglo a un voto ponderado de sus representantes. voto que obviamente se pondera de acuerdo con la composición de la Cámara ${ }^{42}$.

\section{E) El régimen juridico de las encuestas electorales}

La L.O. 5/85 ha venido a reproducir en esta trascendente cuestión el régimen ya establecido por la Ley $14 / 80$, de 18 de abril, sobre régimen de encuestas electorales.

Con esta normativa se sigue una pauta que tiende a generalizarse en el Derecho Comparado y que se orienta a prohibir la publicación de este tipo de encuestas durante un período más o menos prolongado: pero, en todo caso, inmediatamente precedente al día de la consulta popular, pues se estima que con este tipo de encuestas podría llegar a orientarse en un determinado sentido la libre opción de voto de un cierto número de electores, con lo que ello entraña de manipulación del cuerpo electoral.

41 DSCD, II Legialnt:sra, No, 387, 27 mano 1985, pág. 8960.

42 La coumposición do esta Comistón -que el art, 64 del Proyecto denominaba Comisión de Con trol para Radio y Teleristion - constituiria uno de los aspectos más discutidos de esta ley il Gobieno Intentaría que quedara integrada "a su tmagen y senacjanza": en el Proyecto sc Soterminata que estaria formada por 9 vocales, de ellos, cuatro representantes de la Adminis. tradón designados por el Gobierno, y los cinco restantes por la Janta Electoral Central, a propueata confunta de las foranaciones que concurrieran a lus elecciones convocadas. Lo crítica de í mayor parte de los Gropos a esta composición daria lugar a una enmienda transaccional del Grapo P. Socialista, presentads duranie el debate en la Comisibn Constitucional, que habria de sor a la postre ol texto definitivo de la ley en esta materin 
Siguiéndose muy de cerca la pauta marcala en Francia ${ }^{43}$, el art 69 de la L.O. 5/85 establece el siguiente régimen de publicación de encuestas electorales:

a) Queda prohibida la publicación y difusión de sondeos electorales por cualquier medio de comunicacion durante los cinco dias anteriores al de la votación.

b/ Se obliga a los realizadores de todo sondeo o encuesta a que la acompafien de una serie de especificaciones que prevé el art. 69.1 (caracteristicas técnicas del sondeo, texto integro de las cuestiones planteadas ... etc. y y que, asimisma debe incluir toda publicaciôn de las mismas,

c) Se encomienda a la Junta Electoral Central la vigilancia para que los datos e informaciones de los sondeos publicados no contengan falsificaciones, ocultaciones o modificaciones deliberadas.

d/ Los medios informativos que publicaran o difundieran un sondeo, conculcando las disposiciones legales, vienen obligados a publicar y difundir en el plazo de tres dias las rectificaciones requeridas por la Junta Electoral Central.

e/ Por último, las resoluciones de la Junta Electoral Central sobre materia de encuestas y sondeos quedan sujetas a recurso contencioso-administrativa sin que sea preceptivo en este supuesto el recurso previo de reposición (recurso administrativo previo al contencioso que debe ser resuelto por el mismo órgano que dictó el acto recurrido).

\section{F) La concreción legal de los gastos y subvenciones electorales}

Ya en la Exposición de Motivos del propio Proyecto de Ley se consideraba como una novedad, respecto de la normativa precedente, la ordenación de los gastos y subvenciones electorales y su procedimiento de control. Y, en efecto, el capítulo 7 del título I regula con minuciosidad todo lo relativo a esta cuestión, a diferencia del Decreto-ley 20/77 que. aun contemplando los gastos electorales (artículos 44 a 48), procedía a una regulación muy superficial del tema.

43 En Frascia fue regulada esta materia por la Ley No, 77-808, de 19 de julio de 1977, relativa a Is publicación y a la difusión de ciertas encuestas de opinib́n, aquéllas que tienen una rela ción directa o indirecta con un referdndum, ana elección presidencial o una de las elecciones reguladas pot el "Code éitectual"; asi como la elección de los representantos a la Asambiea de Comuaddades Europeas. El art. 11 de esta ley prohibe que en la semana que precede al escretiaio, asi como durante sa desarrollo, se publiquen o difusdan estos sondeos 
Como novedad más destacada, es preciso aludir a la limitación legal de los gastos electorales; esto es, de los que realicen las formaciones politicas participantes en unas elecciones, desde el día de la convocatoria hasta el de la celebración, por una serie de conceptos que enumera el art. 130 de la ley.

Ningún partido o coalición puede realizar gastos electorales que superen los limites legales, que por lo que para las elecciones legislativas se refiere, se fijan (art. 175.2) multiplicando por 40 pesetas el número de habitantes correspondientes a la población de derecho de las circunscripciones donde presente sus candidaturas cada formación, pudiéndose incrementar la cantidad resultante en razón de 20 millones de pesetas por cada circunscripciòn donde aquélla presente sus candidaturas. Ello puede totalizar para un partido o coalición que presente candidatos en todo el territorio nacional una cantidad aproximada de unos 2.500 millones de pesetas; cantidad que se podría ver incrementada en un 50 o/o de coincidir las elecciones a Cortes Generales con otros comicios por sufragio universal directo ${ }^{44}$

Estas especificaciones se complementan con una serie de restricciones adicionales que se orientan tanto a impedir que fondos públicos puedan dedicarse a la financiación de un determinado partido ${ }^{45}$, como a imposibilitar la excesiva dependencia-por la váa de la financiación-de una formación política respecto a una persona física o jurídica ${ }^{46}, y$ todo ello presidido por el principio de la transparencia ${ }^{47}$, y coronado

44 Estas cantidades se prevén en pesetas canstantes, por lo que mediante Orden del Ministerio de Econoenia y Hacionda deberá fijat las cantidades actualizadas en los cinco días siguientes

45 A tal efecto, el art, 128.1 prohibe la zportación \& las "czuentos elecrorales" de cada formacíon de fondos provenientes de cualquier Administración o Corporación póblica, Organismo Autónomo o Entidad paraestatal, o de empresas del sector público cuya titularidad corres. ponda al Estado, a las Comunidades Autónomas, a las Provincias a a los Municipios, y de las empresas yoe, mediante contrato vigente, prestan servicios o realizan suministros u obras para alguna de las Administractones Fúblicas. Aseimismo, el ast. 128,2 prohibe la aportación a estas cueatas de fondos procedentes de estidades o personas extranjeras.

46 Precisameate, para evitar osa dependencia, la ley prescribe que ainguna persona, físáca o jurídiea, podrá aportar más de un millón de pevetas a las catentas electorales de un partido o
coslición.

47 A tal efecto, la LO, 5/85 obliga a toda formación que presente candidaturas en más de ana piovincia a contar con un administrador general (además de un administrador electoral en cada provincia en que preseate candidatos) que responde de todos los iagresos y gastos electorales y de la correspondiente contabilidad Iguelmente, se establece la obligacibn legal de que todos los fondos destinados a sufragar los gastos electorales se ingresen en unas cuentas especificas abiertas para la recaudación de fandos, y con cargo a las cuales deben pagarse todos los gastos electorales. Exige la ley, asimatsm la publicidad de lo identidad de quienes aporten fondes a propios partidos 
por un estricto control de la contabilidad electoral ${ }^{4 t}$

En contrapartida a las limitaciones precedentes, la nueva normatrva no solo - al igual que ya se establece en el Decreto-ley 20/77-mantiene el principio de subvención por el Estado de los gastos ocasionados a los partidos por su concurrencia a las elecciones de diputados y senadores y a las municipales, sino que los eleva en. aproximadamiente, un $40 \% / \mathrm{o}^{4 y}$

\section{EL SISTEMA ELECTORAL PARA LAS ELECCIONES DE DIPUTADOS Y SENADORES}

El sistema electoral, tanto para la elección de Diputados como para la de Senadores, es uno de los aspectos en que menor numero de modificaciones se han introducido en la nueva legislación electoral Prácticamente, permanece intangible el que ya se fijase por el Decreto ley $20 / 77$

A. Por to que al sistema electoral del Congreso de los Diputados se refiere, son numerosas las variables que inciden sobre el:

a) El número total de diputados, que se mantiene en 350 Crecmos que con esta decisión se ha perdido una inmejorable oportunidad de introducir un elemento de potenciación de la proporcionalidad global

45 A la Juata I Iectoral Central y a las Provinciales corresponde velar pot el camplaniento de las normas legales en materia de gastos y subvencsones desde la fecha de la cunvocatoria hasta el centésinso dia postenor a los comicioa. La key exige que los partidos que deban reciber sulvenchones presenten ante el Tribuaal de Cuentas, entre los 100 y 125 dias subajpuientes a las elec ciones, una contabilidad detallada de sus respectivos ingreson y pastos electorales. Dentro de los 200 dias posterioces a los comicios, el Tribanal habri de pronunciarse, en el ejercicio de so función ficalizadora, sobre la regularidad de las contabilidades electorales, pudiendo proponet. caso de apteciar trregularidades en dicha coatabilidad o violaciones de las restricciones legales en materia de ingresos y gastos, la a a ajudicación o ta reduceión de h sobvención entatal que en cada caso corresponda.

Deniro del plazo anteriosmente citado, el Tribunal debe remith el resultado de su fiscalira ción al Gobieno y a la Coenidión Mixta de ambas Cámaras encargada de las relacienes con el Tribunal.

49 El art 175 de la ley, en relación con las elecciones a diputados y senadores, establece lan caguentes subvenciones: a) Un millón quinientas mil pesetas por cada escaho obtenido en el Congseso o en el Senado; b) Sesenta pesetas pot cada uno de los votos eonseguidos pot cads candidatura al Congeso, uno de cuyos miembros, al menos, hubiera obtenido ekafo de diputado; $y$ c) Veinte peietas por cada uno de los votos conseguidos pot cada candidato que hubiera obtenido excaho de senador 
del sistema, incrementando el total de diputados hasta el míximo constitucionalmente permitido: 400 . Con ello se habria elevado el tamano medio de nuestras circunscripciones electorales ( 52 en total: las 50 provincias más Ceuta y Melilla) que hubiera pasado de $677(350: 52)$ a $7 \% 6$ (400:52); y, por ende, se habria logrado una mayor proporcionalidad, meta ésta necesaria si se atiende a que nuestro sistema, bien es verdad que como consecuencia de la incidencia conjunta de todas las variables que sobre él repercuten, distorsiona sensiblemente esa proporcionalidad $^{50}$.

b/ La determinación del tamaño de las circunscripciones, que se lleva a cabo con arreglo a moldes semejantes a los existentes en la normativa precedente; esto es, asignación a cada provincia de un minimo inicial de dos diputados ( $\mathrm{y}$ uno a cada una de las poblaciones de Ceuta y Melilla) y reparto de los restantes escaños -248 - entre las provincias en proporción a su población. Habrá de ser el Decreto de convocatoria de las elecciones el que, en cada caso, especifique el número de diputados a elegir en cada circunscripción.

En este punto, la L.O. 5/85 se separa del Decreto-ley $20 / 77$, que procedía a asignar a cada circunscripción el número de diputados que habia de elegir, que resultaba por lo demás de la suma de los dos escaños que se atribuian a cada provincia a aquellos otros que le correspondieran con arreglo a la proporción de uno por cada 144.500 habitantes o, restos de población superiores a 70.000 .

Evidentemente, el criterio legal actual, que parece más lógico. se justifica en base a que la ley no pretende regular una sola elección. como acaecía con el Decreto-ley de Normas Electorales, sino regir de modo indefinido los sucesivos comicios que tengan lugar en nuestro pais $\mathrm{Y}$ es obvio que en Espafla, quizá incluso más acentuadamente que en otros paises europeos, se producen importantes movimientos migratorios de

50 En las eleciones de 1977. UCD y PSOE contabilizaton, eonjuntamente considerados, usa prima electoral (Aiferencia entre el porcentaje de escanas y el de votos) positiva de $16^{\prime \prime} 16$, que venia a mponer an indice de distorsión de la proporcionabidad de 1 '25 (el indice igaal a la unidad marea la perfecta represeatación, esto es, aquella que se ajusta con exactitud a los votos obtenidas). En los conicios de 1979, h prime electoral de las dos formaciones preci tadas fae de +17 '12, que traducia un indice de distorsión de $1^{\prime} 26$. En las elecciones generales de 1982, PSOE y AP conseguian una prima electotal conjunta de $1.12^{\prime} 97$, que vesia a segmfitar an indice de distorsib́n de 1'17 
población en el interior de nuestro territorio ${ }^{51}$, lo que hace aconsejable proceder a fijar antes de cada elección general el numero exacto de diputados que habrán de elegirse por cada circunscripción.

En otro orden de consideraciones, cabe significar que la resultante de este modelo de distribución circunscripcional de tscaños, en buena medida exigido por la Constitución, es un conjunto amplísimo de distritos de tamaño muy reducido (más de la mitad de las circunscripciones no alcanzará el umbral del tamano 6 , considerado por la doctrina como imprescindible para que un sistema proporcional pueda generar efectos auténticamente proporcionales); $y$, de otro lado, una clara quicbra del principio constitucional de "igualdad de sufragio".

Como al respecto advierte Torres del Moral 52 , el principio de "igualdad de sufragio" añade al principio tradicional de "un hombre, un voto" la idea del valor igual de cada voto, por lo que hoy es enunciado bajo el rótulo de "one man, one vote, one value". Y es que, como seflalara el Presidente del Tribunal Supremo de los Estados Unidos, Juez Warren, en la sentencia "Reynolds versus Sims", de 15 de junio de $1964{ }^{53}$

"Los legisladores representan personas, no árboles o campos. Los legisladores son elegidos por los electores, no por granjas. ciudades o intereses económicos (...). Es inconcebible que una ley que tienda a multiplicar los votos de los ciudadanos por dos. cínco o diez en una región del Estado, mientras en otras los contabiliza por la unidad, pueda ser constitucionalmente admi. sible".

El Juez Warren optaba, pues, como advierte en un completo estudio

51 Esta dituación de desequillbrio poblacional, contra to que pudiera pensurse, no woblo tiende a diseninutr, sino que cada ver se acrecienta mis. Si atendemos a ta población de derecho calculada para 1961 y la comparamos con la de 1 de julio de 1982, constatatemos que 23 provincias, esto ea, easl el $\mathbf{5 0}$ o/o del total, han visto disminair el nimero de sus habitantes, mientras que idéntica comparación efectuads entre 1975 y 1982 . nos depara que 24 provincias han soguido perdiendo pobludón. Es decit, los desequilibaios internos se mantienen, incluso acentuadamente. Cfr, al efecto los datos suminisuados por el Jisrituto Naciovid de Eirtadís. rica: "Anuario Estadístico de Espafia", Madrid, 1983.

52 Antonto Torrea del Moral: "Composición del Congreso de los Diputados", en Hevista de la Facultad de Derecho de la Universidad Complutense, No. 58, invierno 1980, pógs. 29 y sigs. en concreto, píg. 41.

53 "Reynoida versus Sims", 377 U.S. 533; 84. Ct. 1362 (1964). Para an mayot detalle sobre esta sentencia, eft. Ferre Murignon: "Les arstis de la Cour Supteme sur ke redéccepage des circoss. criptions électorales", en Revue du Droit Public et de la Sicence Pobitique, 1967. páes. 694 y siga.; en concreto, páp. 724-729. 
sobre esta problemática Pierre Vialle ${ }^{54}$, por la exigencia de una igualdad matemática precisa, que no debia entenderse tanto en el sentido de una igualdad matemáticamente perfecta, cuanto en el de una llamada a una "representación justa y efectiva" 55 .

Pues bien, esto es precisamente lo que no encontramos en el reparto de escaños que lleva a cabo nuestra legislación electoral. Baste,a titulo de ejemplo, con advertir que si atendemos al censo de 1981, a Madrid le corresponderán 33 escaños y at Soria 3. Pues bien, el índice de representación de ambas circunscripciones serí de 0’75 para Madrid y 3'26 para Soria (56); si confrontamos uno y otro, nos damos cuenta de que la provincia de Soria está 4'3 veces más representada que la de Madrid, lo que, obviamente, extraña una sensible quiebra del principio de igualdad de sufragio".

c/ La fórmula electoral, que se inspira -por mandato constitucional- en criterios de representación proporcional optando, dentro de los mismos, por un sistema de distribución de escanos que se realiza de acuerdo con la regla d'Hondt, que resume en una sola operación el funcionamiento del cociente electoral y el cómputo de restos, de conformidad con el sistema de la mayor media.

Aunque suele ser lugar común el aducir que esta fórmula actủa como poderosa correctora del excesivo fraccionamiento de las representaciones parlamentarias, cabe sin embargo esgrimir con Nohlen ${ }^{57}$ que el método d'Hondt casi no influye en nada el fraccionamiento, ni positiva ni negativamente. Serán, como parece obvio, otros factores los que imposibiliten o distorsionen la proporcionalidad; y, entre ellos, el tamano reducido de la mayor parte de nuestras circunscripciones; pues, como Rae significara ${ }^{56}$ tras una serie de comprobaciones empiricas, en circunscripciones

54 Pírre Vialle: "La Cour Supreme et la réptesentation politique aux Etats-Unis" (Nouvel escai sut le gouvernement des juges), L.G.D.J., Paris, 1972, páz. 157.

55 Pierre Vialfe: "La Cout Supréme et la répresentation ....", op. cit., pág. 201.

56 Este indice es el cocjeste de dividir el porcentaje de exafos de la circunscripción de que se trate sobre el total de escaffos del Congreso entre el porcentaje de habitantes de la proviscia sobre el total de la población nacional. Si este cociente es igial a la unidad, habrá ua ua sjustada representación; existirá tanta mayor sobrerepresentación cuanto más se eleve por encima de ta unidad dicho cociente, y tanta más intrarepresentación caanto mis descienda por debajo de la unidad

57. Dicter Nohlen "Análiss del sastequ dectoral espahol", Centro de Investizaciones y Técnicas Potíticas, Madnd, 1977. paz 3

58 Douglon W Roe "The pobtheal consequences of I lectoral Law" Yale I inversity. Press. Neu Haven and tondon za ed 1971 pas 140 
de tamano inferior a scis, el sistema, al margen ya de la fórmula adoptada, opera con efectos autenticamente mayoritarios.

d) La barrera le'gal, esto es, la clátusula por cuya virtud no se tienen en cuenta para la atribución de escaños aquellas candidaturas que no hubieran obtenido, al menos, el 3 o/o de los votos válidos emitidos en la circunscripción. Esta claúsula, también llamada de exclusión. fue aplicada en la República Federal Alemana con indudable éxito en la consolidación del sistema de partidos ${ }^{59}$. Bien es verdad que en la República Federal la conocida como "Sperrklausel" se fija en el 5 o/o $\mathrm{y}$, lo que aùn es más decisivo, se computa a nivel federal, por lo que su operatividad es real;y el sistema es juzgado como bastante exacto en su conjunto ${ }^{60}$, y de otro lado, la referida "barrera legal". como recuerda Otto Bachof "o1, ha sido considerada como plenamente ajustada a la Ley Fundamental de Bonn por la jurisprudencia del Tribunal Constitucional Federal, porque sirve a la capacidad funcional de un Estado parlamentario de partidos.

Ahora bien, en España la clíusula de exclusión nos presenta una minima, por no decir nula, operatividad; no ya porque alcanza tan sólo el umbral del $3 \% / 0$, sino, básicamente, porque su cómputo se verifica a nivel de cada circunscripción en particular. Como resulta que las circunscripciones son de un tamaño muy reducido, por lo general, se puede concluir significando que la eficacia práctica de este mecanismo electoral entre nosotros se restringe a las circunscripciones de Madrid y Barcelona, siendo prácticamente nula en el resto de los distritos.

B. Por lo que al sistema electoral del Senado se refiere, cabe senalar tan sólo que la L.O. 5/85 sigue la pauta marcada por el Decreto-ley

59 In análogo sentido. Antonio Lopez Fina. "En totno a la Ley Electoral", en "Sistema", Revista de Ciencias Sociales, No. 16, enero 1977 , págs. 95 y sigs.; en concreto, pág. 108 . Por otro lado, loime Nicolds MuAiz (en "El modelo de un sistema cuasi-mixto: el caso alemán", en forge De Esteban y otros, "Hi proceso electoral", Politeia, Iditorial Labor, Barceloaa, 1977, púgs. 247 y sigs; en conereto, págs, $267-268$ ) cree que is "Sperrklausel" se ha constituido en la pieza clave del fancionamiento del sistema alemán.

60 "The present German ekctoral system is on the whole fair and accurate". En estos términos se manifiesta James $X$. Pollock: "The electoral system of the lederal Repuhlic of Germany. A study in representative pobetnment ${ }^{-}$, en The American Potitical Sicence Review, vol. XIVI. diciemhere 1952, No. 4, piés 1056 y sigs. en concreto, pág 1067

61 Orto Bacholf. "Dereche electoral y dereche de los partidos polincos en la Republaca Federal de Alemania", en Boletín Mexicani de Derestho Comparado. Universidat Nacaonal Auto-

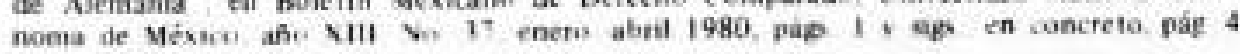


$20 / 77$, estableciendo un voto limitado, que es aquél con el que el elector no dispone de tantos votos como escaños corresponden a una circunscripción. Con ello, y al combinarse este voto con la elección mayoritaria. para formar la elección mayoritaria con voto limitado en circunscripciones plurinominales, se permite, como destaca Nohlen ${ }^{62}$, una representación de la minorfa política.

El art. 166 de nuestra nueva ley electoral prescribe, al efecta que los electores podrán dar su voto en la elección directa de los Senadores a un máximo de tres candidatos en las circunscripciones provinciales (en las que resultan elegidos un total de cuatro senadores), dos en Gran Canaria, Mallorca, Tenerife, Ceuta y Melilla (en las circunscripciones insulares son elegidos tres senadores, mientras que en Ceuta y Melilla corresponde elegir tan sólo dos) y uno en las restantes circunscripciones insulares (Ibiza-Formentera, Menorca, Fuerteventura, Gomera, Hierro, Lanzarote y La Palma), pues a ellas sólo corresponde un senador.

Significaremos por último que, siguiendo una fórmula mayoritaria simple, la ley prevé que "serán proclamados electos aquellos candidatos que obtengan mayor número de votos hasta completar el de Senadores asignados a la circunscripción".

Como única novedad significativa en torno al Senado, $y$ en relación con la normativa anterior, destacar antes de poner punto final que desapa. recen las elecciones parciales de Senadores. En efecto, mientras el art. 21.3 del Decreto-ley 20/77 prescribia que "las vacantes que, dentro de los dos antos siguientes a la fecha de la celebración de las elecciones y por cualquier causa, se produzcan en el Senado, darán lugar a elecciones parciales", el art. 171.2 de la L.0. 5/85 determina que "cada candidatura a Senador debe incluir un candidato suplente", candidato que, caso de fallecimiento, incapacidad o renuncia de un Senador elegido directamente, cubrirá la vacante producida.

62 Dieter Nohlen: "Sistemas electorales del mundo", Centro de Fstudios Constitucionales, Ma-
dris, 1981, pág. 120. 